\title{
Discussões sobre Corredores Ecológicos no Brasil 2006-2016
}

\author{
Ighor Vasques Guedes ${ }^{(a)}$, Tales Miguel Inacio da Silva ${ }^{(b)}$, Raquel da Silva Paes ${ }^{(c)}$, Jose Maria \\ Ribeiro Miro ${ }^{(d)}$
}

(a) Geografia, Instituto Federal Fluminense, vgighor@gmail.com

(b) Geografia, Instituto Federal Fluminense, talesmiguel.th@gmail.com

(c) Geografia, Universidade Federal Fluminense, raquelspaes@hotmail.com

(d) Geografia, Instituto Federal Fluminense, jmiro.geo@hotmail.com

\section{EIXO: BIOGEOGRAFIA, MANEJO DE ÁREAS NATURAIS E PROTEGIDAS: CONSERVAÇÃO DA BIODIVERSIDADE}

\begin{abstract}
Resumo:
Objetivou-se nesse estudo analisar as produções sobre o contexto de corredores ecológicos publicados em periódicos nacionais de Geografia no recorte temporal de 2006 a 2016, atentando para as discussões realizadas para conservação dos ecossistemas e de seus remanescentes. Para isso, a pesquisa foi desenvolvida mediante 4 fases de organização de dados: 1) Levantamento de Periódicos de Geografia de qualis A1, A2 e B1 na plataforma oficial de periódicos da CAPES (plataforma sucupira); 2) Levantamento nas edições das revistas, por artigos científicos que abordassem corredores ecológicos, 3) organização de quadro síntese quanto as variáveis título, área do conhecimento, nome da revista, objetivos, métodos e discussões dos trabalhos e 4) Exposição dos dados das produções de maneira quantitativa e qualitativa. Diante dessa fase de trabalho, objetiva-se futuramente propor um corredor ecológico no entorno do Parque Estadual do Desengano ao Parque estadual da Lagoa do Açu, visando conexão de ambientes e preservação.
\end{abstract}

Palavras chave: Conectividade; Conservação; Ecossistemas; Análise de conteúdo

\section{Intodução}

A Paisagem é um conceito interdisciplinar que analisa os elementos diversificados do espaço. Na ciência geográfica desempenha o papel de categoria e método de análise quando os pesquisadores a utilizam para reflexão teórica sobre o espaço e formulação de suas hipóteses (MOREIRA, 1997). Numa perspectiva geossistêmica, suas análises são realizadas em torno da complexidade e conectividade de seus elementos (BERTRAND, 1971).

Pela perspectiva da Ecologia das Paisagens, ela divide em: 1 - mancha, 2 - matriz e 3 - corredores. As manchas são superfícies não lineares que se diferenciam do seu entorno devido forma, tamanho, entre outros. A matriz define-se como elemento estendido da paisagem que comportam as manchas e corredores de distintos tipos. Os corredores ecológicos são conceituados como formas lineares que permitem o fluxo de espécies de animais e dispersão de vegetais, integrando elementos da paisagem (FORMAN, 1995). Suas discussões vêm sendo acompanhadas da identificação das causas de fragmentação dos ecossistemas. 
Sobre isso, destacam-se as fragmentações ocasionadas por áreas intensamente urbanizadas (CORREAA et $a l .$, 2005) e de grande expansão agrícola (FARIA e CASTRO, 2007).

No Brasil o estabelecimento de corredores ecológicos como ferramenta para diminuir a fragmentação dos ecossistemas e promover a conectividade de seus remanescentes têm sido realizado pelo Ministério do Meio Ambiente através do Projeto Corredores Ecológicos que faz parte do Programa Piloto para Proteção das Florestas Tropicais no Brasil. Sua base legal é regulamentada pela Lei 9985/2000 em que se institui o Sistema Nacional de Unidades de Conservação (SNUC) e na Resolução CONAMA 09/1996 (CORRÊA $e t$ al., 2006). Outros estudos têm apontado o potencial dos corredores ecológicos pelo país a partir das matas ciliares, devido a grande rede de drenagem existente no país. Sua dinâmica de estabelecimento seria fundamental na conservação de diversas espécies inclusive para aquelas que têm habitats nessas áreas (CASSATI, 2010; FREITAS, 2010; GALETTI et al., 2010).

O planejamento e regras de ocupação dos corredores ecológicos são normatizados pelo Plano de Manejo da Unidade de Conservação (UC) em que ele esteja associado. Dentre os dados dos corredores que são acompanhados está a sua extensão com o objetivo de conservação dos habitat da vida nativa e das sociedades humanas do entorno.

Diante da importância dos corredores ecológicos para conservação da biodiversidade e integração de remanescentes, objetiva-se nesse estudo analisar as produções acadêmicas sobre o tema corredores ecológicos, publicados em periódicos nacionais de Geografia no recorte temporal de 2006 a 2016, atentando para as discussões realizadas e as tendências de abordagens para conservação dos ecossistemas.

Este trabalho se insere num projeto de pesquisa intitulado "Análise comparativa de comunidades tradicionais em Unidades de Conservação: conflito socioambiental x etnoconservação" em andamento no Instituto Federal Fluminense, que discute comunidades tradicionais localizadas no entorno de UC no norte do estado do Rio de Janeiro. A partir dessa etapa, objetiva-se propor a criação de um corredor ecológico que vise conectar os ambientes no entorno de áreas de Proteção Integral em Campos dos Goytacazes.

\section{Materiais e Métodos}

A pesquisa foi desenvolvida em 4 fases: 1) Levantamento de Periódicos de Geografia de Qualis A1, A2 e B1 na plataforma Sucupira da CAPES; 2) Levantamento nas edições das revistas, numa escala temporal de 10 anos, por artigos científicos que abordassem corredores ecológicos; 3) Organização de quadro síntese quanto as variáveis título, área do conhecimento, nome da revista, objetivos, métodos e discussões dos trabalhos; e 4) Organização dos dados coletados de maneira quantitativa e qualitativa. 
O estudo foi embasado na técnica da Análise de Conteúdo, que visa de maneira objetiva e sistemática a descrição de dados (qualitativos e quantitativos). De acordo com Bardin (1994), a exposição dos resultados, obtidos a partir desse método, podem ser quantitativos e qualitativos, embora de maneira distinta. Quantitativamente os dados podem ser expostos a partir das frequências como aparecem nos textos e de forma qualitativa a presença ou ausência de determinada discussão pode retratar contextos fundamentais ao tema abordado.

Dessa maneira, a técnicas pode permitir correlações entre as produções científicas e as variáveis discutidas nos textos. Em literatura especializada sobre o tema, essa técnica tem dupla funcionalidade: aumentar a riqueza exploratória do conteúdo das produções e testar as afirmações e indagações presentes nos textos (SILVA et al., 2004). Assim, a exposição dos dados presentes nos textos analisados neste estudo, foi realizada se atentando para a frequência das discussões de corredores ecológicos e relacionando-o as afirmações e questionamentos das produções.

\section{Resultados e Discussão}

A análise dos textos $(\mathrm{n}=27)$ sobre o tema corredores ecológicos foi realizada a partir de quatro categorias:

1) Planejamento e gestão territorial;

2) Classificação de ambientes para criação de corredores;

3) Conservação de ambientes urbanos;

4) Análise integrada do ambiente.

Os textos categorizados na classe "Planejamento e gestão territorial" $(40,74 \%$; $n=11)$ foram aqueles que apresentaram técnicas de utilização dos corredores ecológicos como forma de gerir o ambiente no qual eles estão inseridos, ou seja, áreas pertencentes às Unidades de Conservação (UC), manchas florestais, fragmentos ou espaços com alto potencial e demanda de preservação, entre outros. Além disso, estas produções se mostraram úteis para seus gestores ou profissionais da área ambiental que trabalhem com esse tema. São artigos que contém métodos e análises práticas, e muitos deles usam o conceito para recuperar fragmentos florestais, trabalhar na sua possível união e assim obter uma área menos fragmentada.

Nessa categoria o uso dos corredores ecológicos e Áreas de Preservação Permanente (APP) são descritos como de fundamental importância para que os objetivos de preservação do ambiente sejam alcançados, 
principalmente os que já aparecem fragmentados. Os corredores ecológicos são importantes para a preservação dos ecossistemas que garantem a manutenção das populações biológicas e a ligação entre áreas protegidas (OLIVEIRA et al., 2015), e quando se fala em conectividade de corredores sempre são citados os seus índices. Além disso, a Ecologia da Paisagem foi utilizada como método e teoria fundamentais nas discussões realizadas. As UC foram relatadas como uma das formas válidas para a gestão do espaço em áreas rurais ou urbanas, pois existe uma base legal para a sua implantação como instrumento de preservação.

Na categoria "Classificação de ambientes para criação de corredores" $(25,92 \% ; n=7)$. Nesta abordagem, os aspectos ambientais ficaram evidenciados como importantes aos estudos da área, como por exemplo, a presença da mata ciliar, proximidades com áreas ripárias, análise e classificação das espécies remanescentes, entre outros. Esta categoria demonstrou que esses aspectos são fundamentais nas análises ambientais, pois tem o intuito de conectar os possíveis fragmentos florestais as conexões físicas e biológicas das espécies.

Os artigos que eram voltados mais para definições, identificações, mapeamentos de espécies, composição de remanescentes e manchas, definidas como remanescentes florestais ou corredores ecológicos. Neles, uso do Sistema de Informação Geográfica (SIG) e da técnica de Geoprocessamento foi indispensável para sua a caracterização. Além de mapeado, os dados dos remanescentes florestais podem ser coletados e elaborados através de modelos matemáticos e biológicos, tais como: coeficiente de Bray Curtis ou Biogeografia de Ilhas.

Nessas discussões, o coeficiente de Bray trouxe contribuições levando em consideração sua organização quantitativa e o método de agrupamento de média de grupo (LIMA et al., 2010). Em relação à teoria da Biogeografia de Ilhas, esta foi relatada devido os fragmentos florestais se comportarem como "ilhas" no sentido de seu suporte de espécies e no balanço entre extinção e migração (OLIVEIRA et al., 2015; PERICO, 2005). Ou seja, há uma relação entre o tamanho da área dos fragmentos para o habitat das espécies e a sua fonte. Além disso, há uma discussão histórica sobre os fragmentos florestais a partir da teoria de Biogeografia de Ilhas, passando pelas teorias das Metapopulações e da Conectividade (REZENDE et al., 2010).

A categoria "Conservação de ambientes urbanos" $(14,82 \% ; n=4)$, se apresentou numa dupla abordagem: na caracterização das áreas das cidades, apresentada por modelos de corredores ecológicos dentro ou próximo dos ambientes urbanos para gerar qualidade social da população; e no questionamento e problematização de fragmentação da paisagem devido à expansão urbana. 
Houveram discussões voltadas para a qualidade social do meio urbano por meio da ocorrência de áreas verdes e corredores ecológicos conectando fragmentos de ambientes naturais. Essa caracterização se destacou por quantificar os ambientes naturais como um importante indicador de qualidade de vida para a população em seu entorno. E isso ocorre pelos benefícios sociais que esses ambientes emanam. Nesse contexto, quando há alteração dessas áreas podem ocorrer alterações do microclima, qualidade do ar ou dos recursos hídricos (FORMAN, 1995).

A presença de Mata Ciliar nas APP foi relatada como fundamental na diminuição de problemas de erosão e assoreamento de corpos hídricos. Além disso, é uma alternativa para diminuição de prejuízos causados pelas inundações, utilizando as APP como áreas verdes urbanas as tornando importantes ambientes de lazer (GUIRAO et al., 2012).

Em relação à problematização da fragmentação florestal devido à expansão urbana, os textos trataram o assunto como importante aspecto a ser considerado na política ambiental urbana. Além disso, relataram que tem ocorrido degradação dos últimos remanescentes de Floresta Ombrófila Densa no Brasil com perda de biodiversidade local. Assim, a perda de áreas de Mata Atlântica causa grande impacto na dinâmica de espécies e que este bioma comporta, pois ele é um dos Hotspots de conservação e abriga diversas espécies endêmicas (MELLO-THÉRY, 2011).

A classe "Análise integrada do ambiente" $(18,52 \%$; $n=5)$ se apresentou nos textos como utilizados para solução de problemas de preservação. Nestas áreas, já continham corredores ecológicos ou apresentavam diagnósticos ambientais para sua criação. Assim, realizavam prognósticos, sugeriam medidas e apontavam as necessidades das áreas quanto à preservação. Nesses artigos, as discussões em comum foram a produção pecuária e a agricultura extensiva, que em muitos casos, utilizam-se de técnicas primitivas para o uso e manejo do solo, como por exemplo: as queimadas, uso de maquinas agrícolas pesadas, o que podem causar a compactação dos solos e dificultar os estudos das áreas com remanescentes florestais e na implantação de corredores ecológicos.

Outras questões abordadas nessa categoria foram a da legislação ambiental e a falta de fiscalização em áreas de proteção ambiental. Um dos artigos chega até ressaltar que existem UC que são áreas judicialmente protegidas por lei, mas que pela falta de fiscalização do Estado acabam se tornando áreas degradadas pelo homem. O que acaba dificultando não só o desenvolvimento da biodiversidade na região, mas também técnicas de conservação e preservação.

Com a categorização realizada foi possível entender como as abordagens comportam variadas situações em diversas escalas espaço temporais. A figura 1, apresentada abaixo, sintetiza a frequência das categorizações identificadas nos textos analisados. 


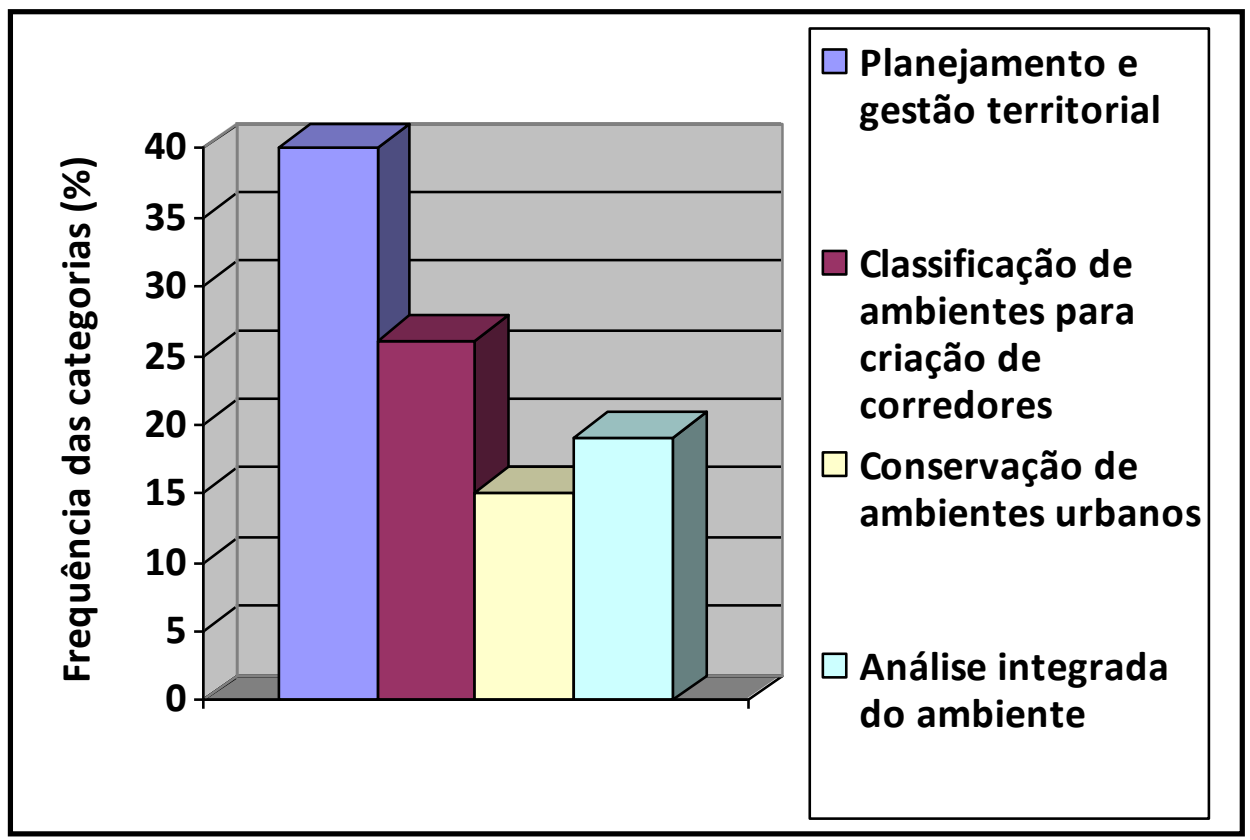

Figura 1 - Categorização das produções consultadas

Fonte: Organização dos autores.

As áreas do conhecimento dos autores das publicações analisadas se apresentaram de maneira diversificada, o que mostra que corredores ecológicos é um tema interdisciplinar, analisado por diversas áreas científicas, agregando contribuições às abordagens. Destacam-se as produções referentes as áreas do conhecimento: Geografia 71\%; Engenharia Florestal 26\%; Biologia 23\%; Engenharia Ambiental 15\% e Ciências Agrárias 12\%. Ainda outros campos científicos foram representados em menor proporção como Ciências Naturais, Geologia, Ciência Florestal, Ecologia, entre outras.

\section{Considerações finais}

Os corredores ecológicos são importantes áreas de conexão de fragmentos florestais, favorece a dispersão de espécies e sua dinâmica de reprodução. Além disso, são instrumentos fundamentais de gestão de áreas de preservação como as UC, que garantem a manutenção e recuperação dos biomas brasileiros.

$\mathrm{Na}$ análise dos trabalhos sobre corredores ecológicos, ficou evidente que a maioria direciona suas discussões ao planejamento e gestão de áreas de UC ou áreas a serem preservadas, realizando caracterizações e identificações de potencialidades biológicas de flora e de fauna. Geograficamente 


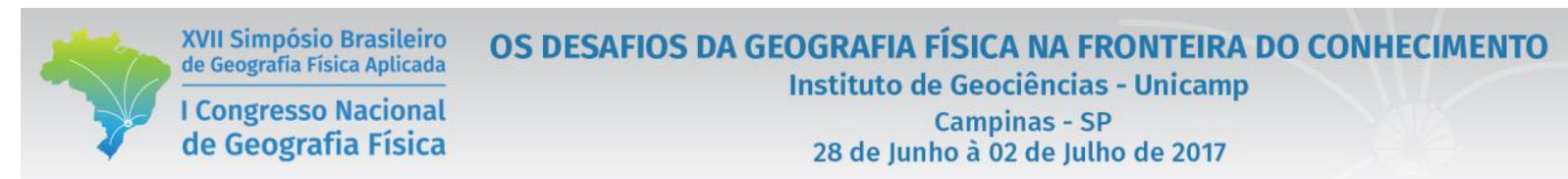

apresentam características espaciais que podem levar a conexão entre áreas naturais ou antrópica. Além disso, há o argumento jurídico normatizado legalmente pelo SNUC.

Não se objetivou finalizar as discussões sobre os corredores ecológicos nesse trabalho e sim fazer uma análise do conceito que está sendo abordado nas produções de periódicos de Geografia em âmbito nacional. Esta fase, além de ser fundamental no conhecimento de discussões, é o primeiro passo para proposição de um corredor ecológico na região norte do estado do Rio de Janeiro, conectando o Parque estadual do Desengano (PED) a lagoa Feia, através do rio Ururaí, como previsto no Plano Diretor do município de Campos dos Goytacazes (Lei 7972/2008). Depois disso, o corredor poderia conectar-se ao Parque Estadual da Lagoa do Açu (PELAG), através do canal da Flecha. Para isso, será necessário um estudo minucioso dessas áreas em termos físicos, biológicos e de uso e ocupação para se entender a viabilidade e efetivação desse objetivo.

\section{Bibliografia}

AVILA, Angela Luciana de; ARAUJO, Maristela Machado; LONGHI, Solon Jonas; GASPARIN, Ezequiel. Caracterização da vegetação e espécies para recuperação de mata ciliar, Ijuí, RS. Revista Ciência Florestal. Santa Maria, v. 21, n. 2, p. 251-260, abr./jun., 2011.

BARDIN, I. Análise de conteúdo. Lisboa: Edições Setenta, 1994. 226 p.

BRASIL. Lei 9985, de 18 de julho de 2000. Institui o Sistema Nacional de Unidades de Conservação da Natureza e dá outras providências. Brasília: Diário Oficial da União. 2000.

BERTRAND, Georges. Paisagem e geografia física global: esboço metodológico. Universidade de São Paulo, Instituto de Geografia, 1972.

CAMPOS DOS GOYTACAZES. Plano Diretor do Município de Campos dos Goytacazes. Lei n. 7.972 de 31 de março de 2008. Campos dos Goytacazes-RJ, Câmara Municipal de Campos dos Goytacazes, 2008.

CÂNDIDO, Anny Keli Aparecida Alves; SILVA, Normandes Matos da; BARBOSA, Domingos Sávio. Dinâmica espacial e temporal do uso do solo e índice de vegetação por diferença normalizada (NDVI) em setor de cabeceira do Rio São Lourenço, Campo Verde, MT. Revista Ra'e Ga. Curitiba, v. 33, p. 94-119, abr., 2015.

CARNEIRO, Gabriel Tenaglia; CABACINHA, Christian Dias; FARIA, Karla Maria Silva de; SIQUEIRA, Mariana Nascimento; LIMA; Júnio César de Souza. Cobertura florestal do município de Rio Verde, GO: estrutura e composição da paisagem entre 2005 e 2008. Revista GEOGRAFIA. Rio Claro, v. 36, n. 2, p. 335-357, mai./ago., 2011.

CASSATI, L. Alterações no código florestal brasileiro: impactos potenciais sobre a ictiofauna. Biota Neotropica, v. 10, n. 4, p. 11-23, 2010.

CORRÊA, Rodrigo Studart; CARDOSO, Eriel Sinval; BAPTISTA, Gustavo Macedo de Mello; MÉLO FILHO, Benício de. Zoneamento do território para a identificação de corredores ecológicos no Distrito Federal. Revista GEOGRAFIA. Rio Claro, v. 31, n. 1, p. 137-149, jan./abr., 2006.

COUTO, Maria do Socorro Duarte da Silva; FERREIRA, Laerte Guimarães; HALL, Bryon Richard; SILVA, Geci José Pereira da; GARCIA, Fanuel Nogueira. Identificação de áreas prioritárias para conservação da biodiversidade e paisagens no Estado de Goiás: métodos e cenários no contexto da bacia hidrográfica. Revista Brasileira de Cartografia. Rio de Janeiro, v. 2, n. 62, p. 125-135, jun., 2010. 
FARIA, Karla Maria Silva de; CASTRO, Selma Simões de. Uso da terra e sua relação com os remanescentes de cerrado na alta bacia do Rio Araguaia (GO, MT e MS). Revista GEOGRAFIA. Rio Claro, v. 32, n. 3, p. 657-668, set./dez., 2007.

FERNANDES, Fernando; FERRONATO, Melânia Zampronho; MORO, Rosemeri Segecin. Rio Pitangui, composição e configuração espacial das unidades de paisagem. Revista da ANPEGE. Dourados, v. 7, n. 8, p. 119127, ago./dez., 2011.

FORMAN, R. Land mosaic: the ecology of landscapes and regions. Cambridge: Cambridge University Press, 1995. 632p.

GALETTI, M.; PARDINI, R.; DUARTE, J. M. B.; SILVA, V. M. F.; ROSSI, A. E.; PERES, C. A. Mudanças no código florestal e seu impacto na ecologia e diversidade dos mamíferos no Brasil. Biota Neotropica, v. 10, n. 4, p.34-45, 2010.

GUIRAO, Ângela Cruz; FONSECA, Marcelo Fernando; CASTELlANO, Marina Sória. Problemática das inundações e sua relação com a situação das Áreas de Preservação Permanente: visão do poder público e o uso de geoprocessamento. Revista do Departamento de Geografia. São Paulo, v. 24, p. 151-168, 2012.

GUISARD, Denise Maria Paes; KUPLICH, Tatiana Mora. Fragmentação da cobertura florestal no município de São José dos Campos (SP) entre 1973 e 2004. Revista GEOGRAFIA. Rio Claro, v. 33, n. 2, p. 319-329, mai./ago., 2008.

LIMA, Michele Soares de; DAMASCENO-JÚNIOR, Geraldo Alves; TANAKA, Marcel Okamoto. Aspectos estruturais da comunidade arbórea em remanescentes de floresta estacional decidual, em Corumbá, MS, Brasil. Rev. bras. Bot. São Paulo, v. 33, n. 3, p. 437-453, jul./set., 2010.

LOCH, Carlos; REBOLLAR, Paola Beatriz May; ROSENFELDT, Yuzi Anai Zanardo; RAITZ, Crisley Silveira; OLIVEIRA, Mirtz Orige. Definição de áreas para formação de corredores ecológicos através da integração de dados em um Sistema de Informação Geográfica. Revista Brasileira de Cartografia. Rio de Janeiro, v. 3, n. 65, p. 455465, mai./jun., 2013.

MARQUES NETO, Roberto. Reservas Particulares do Patrimônio Natural (RPPNS) como estratégia para a conservação da Mata Atlântica e a importância da geografia física nos planos de manejo. Revista GEOGRAFIA. Rio Claro, v. 37, n. 1, p. 95-108, jan./abr., 2012.

MARQUES NETO, Roberto; PEREZ FILHO, Archimedes; OLIVEIRA, Thomáz Alvisi de. Geossistemas na bacia do Rio Verde (MG): proposta de mapeamento de sistemas ambientais físicos em escala regional. Revista GEOGRAFIA. Rio Claro, v. 39, n. 2, p. 321-336, mai./ago., 2014.

MELLO-THÉRY, Neli Aparecida de. Conservação de áreas naturais em São Paulo. Revista Estudos Avançados. São Paulo, v. 25, n. 71, p. 175-188, 2011.

MORAES, Maria Eugênia Bruck de; LORANDI, Reinaldo. Análise dos elementos da paisagem na bacia hidrográfica do Ribeirão do Pântano (SP) como subsídio ao zoneamento ambiental. Revista GEOGRAFIA. Rio Claro, v. 34, n. 3, p. 577-594, set./dez., 2009.

MOREIRA, Ruy. Conceitos, Categorias e Princípios Lógicos para o Método e o Ensino da Geografia. Pensar e ser em geografia: Ensaios de história, epistemologia e ontologia do espaço geográfico. Paulo: Contexto, 2007. p. 105118 ;

OLIVEIRA, Jacson Tavares de; MOREAU, Ana Maria Souza dos Santos; PAIVA, Arlicélio de Queiroz; MENEZES, Agna Almeida; ALMEIDA, Thiara Messias de. Evolução do uso da terra em uma bacia de captação de água do sudoeste da Bahia. Revista GEOGRAFIA. Rio Claro, v. 33, n. 1, p. 141-155, jan./abr., 2008.

OLIVEIRA, Plínio Santos de; MOREIRA, Adriana Aparecida; NERY, César Vinícius Mendes; MELO, Aneliza de Almeida Miranda. Microcorredores ecológicos no entorno do Parque Estadual da Lapa Grande. Revista Caminhos de Geografia. Uberlândia, v. 16, n. 53, p. 189-200, mar., 2015.

PEREIRA, Tiaro Katu; MORO, Rosemeri Segecin; NOGUEIRA, Melissa K. F. de Souza; DIAS, Wolliver. A paisagem da bacia do Rio Pitangui sobre a Escarpa Devoniana, Ponta Grossa, Paraná. Revista Sociedade \& Natureza. Uberlândia, v. 25, n. 3, p. 567-579, set./dez., 2013. 


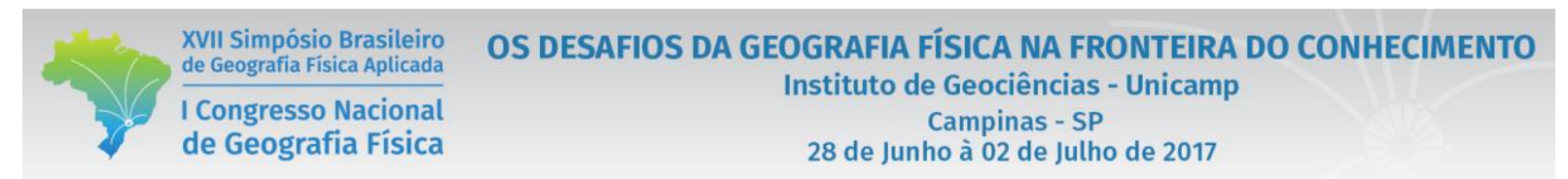

PEREIRA, Vítor Hugo Campelo; CESTARO, Luiz Antônio. Corredores ecológicos no Brasil: avaliação sobre os principais critérios utilizados para definição de áreas potenciais. Revista Caminhos de Geografia. Uberlândia, v. 17, n. 58, p. 16-33, jun., 2016.

REIS, João Rodrigo Leitão dos; PINHEIRO, Eduardo da Silva. Análise do desflorestamento em uma Unidade de Conservação de uso sustentável na Amazônia Central. Revista GEOGRAFIA. Rio Claro, v. 35, n. 3, p. 623-640, set./dez., 2010.

REZENDE, Renato Andrade; PRADO FILHO, José Francisco; SOBREIRA, Frederico Garcia; SANTOS, Thiago Fernandes. Dinâmica da cobertura do solo no extremo sul da Serra do Espinhaço: métricas da paisagem e a conectividade entre áreas protegidas. Revista GEOGRAFIA. Rio Claro, v. 35, n. 3, p. 683-699, set./dez., 2010.

ROCHA, Yuri Tavares. Distribuição geográfica e época de florescimento do Pau-Brasil (Caesalpinia echinata LAM. - LEGUMINOSAE). Revista do Departamento de Geografia. São Paulo, v. 20, p. 23-36, 2010.

SILVA, Cristiane Rocha; GOBBI, Beatriz Christo; SIMÃO, Ana Adalgisa. O uso da análise de conteúdo como uma ferramenta para a pesquisa qualitativa: descrição e aplicação do método. Revista Organ. rurais agroind. Lavras, v. 7, n. 1, p. 70-81, 2005.

SILVA, Maria do Socorro Ferreira da; MELO E SOUSA, Rosemeri. Padrões espaciais de fragmentação florestal na FLONA do Ibura - Sergipe. Revista Mercator. Fortaleza, v. 13, n. 3, p. 121-137, set./dez., 2014.

SPATTI, Eder Paulo Junior; PEREIRA, Luis Henrique; CONCEIÇÃO, Fabiano Tomazini da; PINTO, Sérgio dos Anjos Ferreira; GUEDES, Edvaldo; SILVA, Felipe Augusto Valle. Impactos ambientais na bacia hidrográfica do Ribeirão Monjolo Grande, Ipena, SP. Revista GEOGRAFIA. Rio Claro, v. 37, n. 3, p. 477-491, set./dez., 2012.

THOMAS, Bruna Letícia; THOMAS, Pedro Augusto; FOLETO, Eliane Maria. A relevância da criação de uma Unidade de Conservação no Morro Gaúcho, municípios de Arroio do Meio e Capitão/RS. Revista do Departamento de Geografia. São Paulo, v. 27, p. 112-130, 2014.

TRAJANO, Eleonora. Políticas de conservação e critérios ambientais: princípios, conceitos e protocolos. Revista Estudos Avançados. São Paulo, v. 24, n. 68, p. 135-146, 2010.

WATRIN, Orlando dos Santos; GERHARD, Pedro; MACIEL, Maria de Nazaré Martins. Dinâmica do uso da terra e configuração da paisagem em antigas áreas de colonização de base econômica familiar, no nordeste do Estado do Pará. Revista GEOGRAFIA. Rio Claro, v. 34, n. 3, p. 455-472, set./dez., 2009.

ZIEMBOWICZ, Taciana; MARENZI, Rosemeri Carvalho; ESPINOZA, Helia del Carmen Farías. Análise do uso e cobertura do solo dos promontórios costeiros do litoral centro-norte de Santa Catarina. Revista Geosul. Florianópolis, v. 29, n. 57, p. 43-64, jan./jun., 2014. 